\title{
Hematuria in a Patient with Persistent Left Cardinal Vein Crossing Retroaortic to the Right Cardinal Vein (Inferior Vena Cava)
}

\author{
Erich K. Lang, Quan D. Nguyen
}

Department of Imaging (EKL), Johns Hopkins Medical Institutions, Baltimore, Maryland, USA and Department of Radiology (EKL, QDN), SUNY Downstate Medical School, Brooklyn, New York, USA

This 52-year-old Caucasian male presented with microscopic hematuria and bouts of gross hematuria increasing in frequency. Four prior urologic work-ups, consisting of cystoscopy, IVUs, ultrasound examinations, urinalysis performed during the last 15 years had failed to identify a cause for the hematuria.

At admission, a well nourished male, with essentially normal laboratory findings, $\mathrm{Hb} 14.8 \mathrm{gm}$, Hct 41, RBC 5.1 mil, WBC 5800, BUN 18 mg/dl, potassium $4.6 \mathrm{mEq} / \mathrm{L}$, creatinine $0.9 \mathrm{mg} / \mathrm{dl}$, glucose $92 \mathrm{mg} / \mathrm{dl}$, alk ptas $108 \mathrm{U} / 1$, however, showed abnormal urinanalysis 8-10 RBC / hpf, 1-2 WBC / hpf, spec grav 1014.

Physical examination revealed mild edema of the lower extremities, and minimal venous distension of both right and left dorsal pedal veins. Otherwise, no abnormalities were noted. Once again cystoscopy was unremarkable.

A contrast enhanced multi-detector computed tomography discovered major abnormalities of the inferior vena cava (IVC) and renal veins.

The right and left common iliac vein joined to form a left inferior vena cava, (persistent left cardinal vein) and ascended to the left of the aorta (Figure-1). The left renal vein descended steeply and then emptied into the left IVC. The left IVC then crossed under the aorta to continue on the right side after receiving flow from the right renal vein (1). The left IVC prior to its passage under the aorta appears to be distended (Figure-2).
Left retroaortic renal vein and compression of the left renal vein in its passage between superior mesenteric artery and aorta are a well recognized cause for hematuria (2), resultant increased pressure in the left renal vein causes bleeding. The compression of the left inferior cardinal vein at its passage

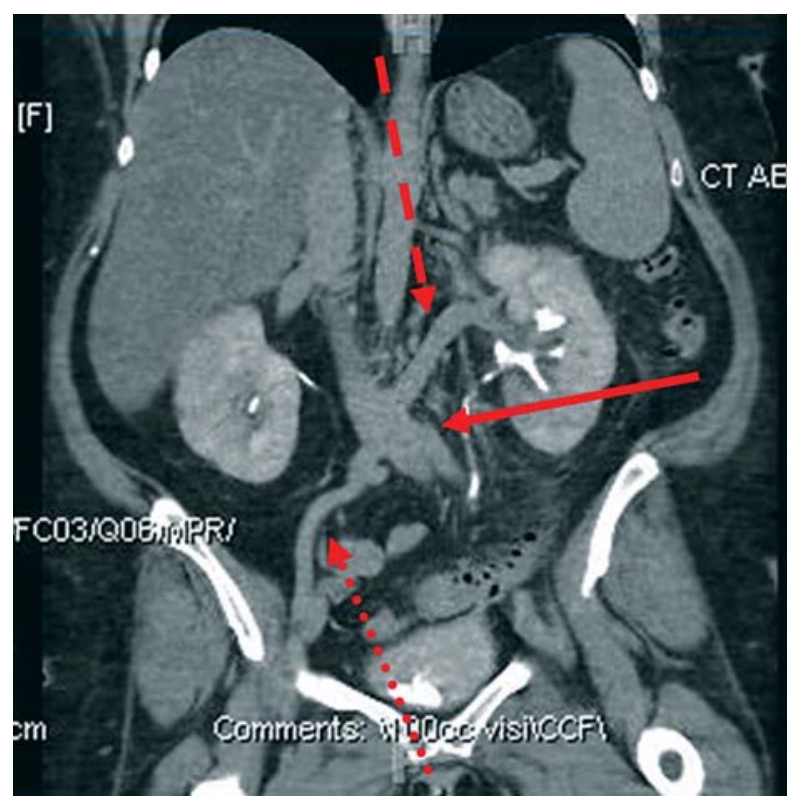

Figure 1 - Dilated segment of left inferior vena cava. Note persistent left inferior cardinal vein (arrow) and anomalous left renal vein descending and entering into inferior cardinal vein (dotted-arrow) and right iliac vein entering inferior cardinal vein (pointed-arrow). 


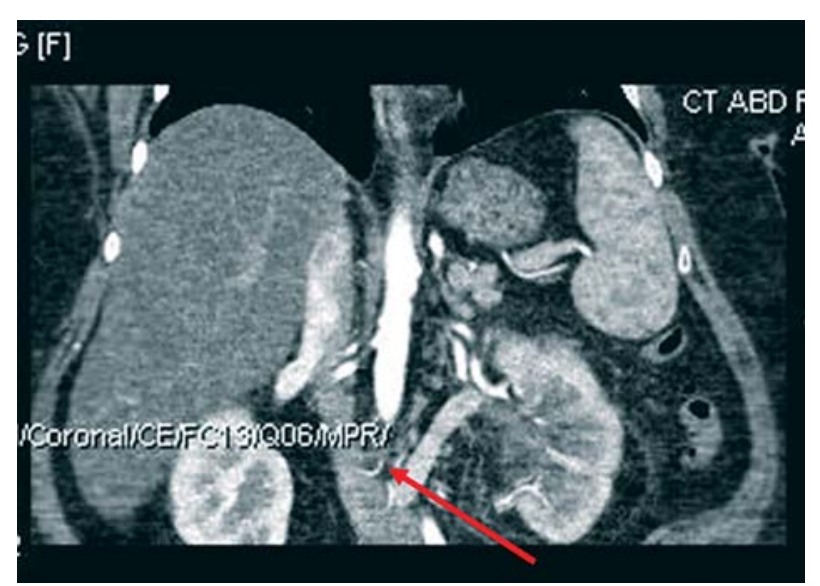

Figure 2-An earlier phase demonstrates the point of crossing of the left inferior vena cava (persistent inferior cardinal vein under the aorta - note the dilated anomalous left renal vein indicating increased pressure).

\section{Correspondence address:}

Dr. Erich K. Lang

Department of Radiology

SUNY Downstate College of Medicine

450 Clarkson Avenue

Box 1198, Brooklyn, NY, 11231, USA

Fax: + 1 718-270-3848

E-mail: erich.lang@downstate.edu under the aorta similarly increased pressure, which because of the location of the left renal vein in our patient was transmitted to the left renal vein $(1,2)$. The striking dilatation of the left cardinal vein attests to the hemodynamic significance.

\section{REFERENCES}

1. Natsis K, Apostolidis S, Noussios G, Papathanasiou E, Kyriazidou A, Vyzas V: Duplication of the inferior vena cava: anatomy, embryology and classification proposal. Anat Sci Int. 2010; 85: 56-60.

2. Gupta A, Naik N, Gulati GS: Mesoaortic entrapment of a left inferior vena cava. Indian J Radiol Imaging. 2010; 20: 63-5. 